\title{
A MODIFIED NEOCLASSICAL GROWTH MODEL WITH ENDOGENOUS LABOR PARTICIPATION
}

\author{
Delano Segundo Villanueva \\ Department of Economic Research, Bangko Sentral ng Pilipinas, Manila, Philippines. \\ Email: dansvillanueva@gmail.com
}

\begin{abstract}
In light of robust econometric results on the determinants of labor participation in 36 advanced economies reported by Grigoli et al. (2018) and independently by CBO (2018), my paper modifies the Solow (1956) - Swan (1956), or S-S, growth model by making endogenous the rate of labor participation (exogenously fixed at a constant fraction of population in the S-S model). By allowing a fully adjusting natural rate, I find that the positive growth effects of a higher saving rate hold in the transition to and in the steady state (a generalization of the S-S model).
\end{abstract}

Keywords: Neoclassical growth; Technical change; Labor participation, Growth policies. JEL Classifications: E130; J220; O41.

Article history:

Received : October 21, 2019

Revised : December 28, 2019

Accepted : February 28, 2020

Available online : February 29, 2020

https://doi.org/10.21098/bemp.v23i1.1175 


\section{INTRODUCTION}

Assume an aggregate Cobb-Douglas production function,

$$
Y=K^{\alpha} L^{(1-\alpha)}
$$

where $Y$ is output, $K$ is the capital stock, $L=A P N$ is effective labor (in efficiency units), $\alpha$ is the elasticity of output with respect to capital, and 1- $\alpha$ is the output elasticity with respect to labor. $A$ is a labor-augmenting (or Harrod-neutral) technology multiplier, $P$ is labor participation (a positive fraction), and $N$ is total population. Output growth is equal to the weighted sum of capital growth and labor growth, the weights being $\alpha$ and 1- $\alpha$, respectively. Capital growth is the warranted rate and labor growth is the natural rate. The warranted rate is:

$$
\frac{\dot{K}}{K}=s \frac{Y}{K}-\delta
$$

where $s$ is the fixed gross saving/income ratio and $\delta$ is a constant depreciation rate. From the definition $L=A P N$, labor growth is given by

$$
\frac{\dot{L}}{L}=\frac{\dot{A}}{A}+\frac{\dot{P}}{P}+\frac{\dot{N}}{N}
$$

Let $k=K / L$ be the level of capital intensity. In the steady state, if it exists, $k$ is constant at $k^{*}$, which means that

$$
\frac{\dot{K}}{K}=s \frac{Y}{K}-\delta=\frac{\dot{L}}{L}=\frac{\dot{A}}{A}+\frac{\dot{P}}{P}+\frac{\dot{N}}{N} .
$$

And by the constant-returns assumption,

$$
\frac{\dot{K}}{K}=\frac{\dot{L}}{L}=\frac{\dot{Y}}{Y}
$$

defining the steady-state growth rate of output $Y$, or the balanced growth path. The knife-edge Harrod (1939)-Domar (1946) problem is expressed by the condition

$$
\frac{\dot{K}}{K}=\frac{S}{v}-\delta \gtreqless \frac{\dot{L}}{L}=\frac{\dot{A}}{A}+\frac{\dot{P}}{P}+\frac{\dot{N}}{N} \gtreqless \lambda+\mathrm{n},
$$

where $v=K / Y$ is the fixed capital-output ratio, $\frac{\dot{A}}{A}=\lambda, \frac{\dot{P}}{P}=0$, and $\frac{\dot{N}}{N}=$ n, where $\lambda$ and $n$ are constants. Balanced growth, macroeconomic stability, and full employment are not assured. 
Solow (1956) and Swan (1956), hereafter S-S, solved the knife-edge Harrod (1939)-Domar (1946) problem by employing a neoclassical production function with smooth substitutability between capital and labor, i.e., $v$ is a monotonically increasing function of the capital-labor ratio, $k$, such that the warranted rate (saving-investment) fully adjusts from any initial level of capital intensity, making balanced growth possible.

However, the steady state remains exogenous because the natural rate (effective labor growth), which is fixed at $\lambda+n$ by assumption, remains the bottleneck in the growth process, with the result that the positive growth effect of a higher saving rate, $s$, during the transition ${ }^{1}$ disappears in the steady state.

The 1960s through 1990s saw attempts to solve the S-S model's exogeneity of the natural rate, $\frac{\dot{A}}{A}+\frac{\dot{P}}{P}+\frac{\dot{N}}{N}$, by making technical change $\frac{\dot{A}}{A}$ endogenous. $^{2}$ An early learning-by-doing model by Arrow (1962) found that learning has a positive effect on the steady-state growth of output, but the latter is independent of the saving rate. Nelson and Phelps (1966), Conlisk (1967), and Villanueva (1994) ${ }^{3}$ advanced early models with endogenous labor-augmenting technical change, deriving the key result that the growth effect of an increased saving rate does not vanish in the steady state.

Subsequent contributions constructed increasingly complex models. Romer $(1986,1990)$ posited a knowledge-producing sector, alongside a goods-producing sector. The stock of knowledge is a non-rival good-its use in one sector does not preclude its use in the other sector. The steady-state growth rates of knowledge, capital, and per capita output are constant and independent of the saving rate. Lucas (1988) proposed models emphasizing human capital accumulation through schooling and learning-by-doing, but he abstracted from the economics of demography. ${ }^{4}$ Grossman and Helpman (1991) focused on innovation financed by investments in industrial research. Rebelo's (1991) AK model assumed that all productive inputs, including human capital, are reproducible capital. ${ }^{5}$ Aghion and Howitt (1998) highlighted imperfect markets in the R\&D sector and Schumpeterian creative destruction. The knowledge-innovation-R\&D sector is assumed to be subject to increasing returns, so that growth does not vanish in the long run. Conlisk (1967) has shown that increasing returns to capital yield explosive growth, which rarely happens in the real world. He has demonstrated that a growth model with endogenous labor-augmenting technical change and

1 Temporary growth as Solow (1991, p. 4) calls it.

2 For an engaging history of endogenous growth theory, see Warsh (2007). Solow (1991) has been critical of endogenous growth models with their emphasis on endogenous technical change and increasing returns.

3 Agenor (2004, pp. 466-471) refers to Villanueva's (1994) model as “An extension of Arrow's (1962) learning-by-doing model...."

4 Lucas $(1988$, p. 6) admits that this is a serious omission.

5 Output $\mathrm{Y}=\mathrm{AK}$, where $\mathrm{Y}$ is constant returns to capital $\mathrm{K}$, implying that $\mathrm{Y}$ always grows at the same rate as $K$, and is equal to $s^{*} A$, where $s^{*}$ is the fraction of income saved for investment in physical and human capital ( $\mathrm{s}^{*}>\mathrm{s}$, where $\mathrm{s}$ is income saved for investment in physical capital) and $\mathrm{A}$ is a technological constant. This property is in sharp contrast to the transitional growth dynamics in the S-S model. 
an aggregate production function that is subject to diminishing returns to capital is consistent with the proposition that the positive growth effects of an increased saving rate (or of any change in the other model parameters) do not cease in the steady state.

In all the above growth models, the labor participation rate, $P$, is an exogenous constant fraction by assumption. ${ }^{6}$ Another solution to the knife-edge problem, besides the S-S model's variable capital-output ratio implicit in a well-behaved neoclassical production function with smooth factor substitution and wagerice flexibility, is a fully-adjusting natural rate via an endogenously-determined labor participation rate, $P$. In a carefully researched IMF empirical study, Grigoli et al. (2018, Table 1, p. 18) found robust results that, among others, an increasingly educated ${ }^{7}$ labor force influenced significantly and positively labor participation rates in 36 advanced economies. Referring to the U.S., in particular, the Congressional Budget Office (CBO, 2018) issued a working paper on labor participation, containing similar explanatory variables included in the IMF study, and arriving at similar statistical results. The study noted that the U.S. labor participation rate began an uninterrupted decline in the latter half of the 1990s, coinciding with the aging and retirement of baby boomers. In 2007, the labor participation rate stood at 66\%. A decade later, in 2017Q4, it fell to $63.2 \%$. CBO projects that the U.S. labor participation rate will continue to decline and will be $60.2 \%$ in 2028 Q 4 . The projected increase in educational attainment, which has a positive effect on the labor participation rate, will not be enough to offset the continued decline attributed to aging and retirements, and to the stagnation in real wages, among other factors.

Motivated by the empirical findings of Grigoli et al. (2018) and CBO (2018), the current paper postulates that the proportionate change in labor participation consists of exogenous components including aging and retirements, and endogenous components including aggregate income per man-hour and real wages. The objective and hence novelty of the present paper is to generalize the steadystate property of the S-S model by making the natural rate fully adjusting through endogenous labor participation, $P$, i.e., a non-zero variable $\frac{\dot{P}}{P}$, while retaining the twin assumption of $\frac{\dot{A}}{A}=\lambda$ and $\frac{\dot{N}}{N}=\mathrm{n}$. To elaborate, in the effective labor definition $L=A P N$, the S-S model assumes that $P$ is a constant fraction of population, $N$, and, thus, $\frac{\dot{P}}{P}=0$. It also assumes that $A$ and $N$ are exogenous variables growing at constant rates $\lambda$ and $n$, respectively. The natural rate can be made fully-adjusting by assuming that either $A, P$, or $N$ is endogenously determined. Some endogenous growth models [Nelson and Phelps (1966), Conlisk (1967), and Villanueva (1994)]

\footnotetext{
6 Whether it is $70 \%$ or any other percentage, the rate of change in $\mathrm{P}$ is assumed to be zero. The labor participation rate and unemployment rate are metrics used to gauge the health of the labor market. The key difference between the two indicators is that the participation rate measures the percentage of people who are in the labor force, while the unemployment rate measures the percentage within the labor force that is currently unemployed.

Workers with secondary and tertiary degrees.
} 
make the case for an endogenous $A$. The present paper, considering the work of Grigoli et al. (2018) and CBO (2018), makes the case for an endogenous $P$.

\section{THE BASIC NEOCLASSICAL (S-S) GROWTH MODEL: A BRIEF REVIEW}

The centerpiece of neoclassical aggregate growth theory is a production function of the form

$$
Y=F\left(X_{i}, A\right)
$$

linking output $Y$ to a set of factor inputs $X_{i}$ and technology $A$. The function $F($.) is assumed to exhibit diminishing returns to $X_{i}$ and $A$ separately, and constant returns jointly. The $X_{i}$ typically includes capital $K$ and labor $L$, while the technology input $A$ refers to the stock of technical know-how or blueprints. In neoclassical models with balanced steady-state growth paths (of the S-S variety) the technology variable $A$ is typically assumed to be labor-augmenting or Harrod-neutral. The stock of physical capital, $K$, is assumed to grow at a rate equal to the proportion of output saved and invested, $s$, multiplied by the output-capital ratio, $Y / K$, less the rate of capital depreciation $\delta$, as in Equation (2). Owing to diminishing marginal product of capital, $Y / K$ is a monotonically declining function of the ratio of $K$ to $L$. Capital growth, Equation (2), is termed the warranted rate. Labor growth, Equation (3), is termed the natural rate, proceeding exogenously as $\lambda+n \cdot{ }^{8}$ Given these assumptions, on the balanced growth path the limiting factor to the steady state (long-run) growth rate of output is the natural rate $\lambda+n$, independent of the saving rate $s$.

Even though its prediction that the long-run growth rate of output is unaffected by changes in the saving rate appears to be counter-intuitive, the S-S model is nevertheless rich in transitional dynamics. Given a rising (falling) value of $K / L$, output growth is larger (smaller) than the steady-state rate $\lambda+n$. Also, since the rate of capital accumulation is a positive function of the saving rate, an increase in the latter, via for instance, changes in fiscal policy, can raise the transitional growth rate of output.

\section{THE MODIFIED GROWTH MODEL}

I retain the S-S model's assumption of fully exogenous rates of labor-augmenting technical change, $A$, and population growth, $N$. The only modification I make is to rely on the IMF and CBO empirical studies to justify that the labor participation rate, $P$, is not a constant but a variable that is partly endogenous and partly exogenous (for explanation, see Section III.A below). Figure 1 is a schematic presentation of the model.

$8 \frac{\dot{P}}{P}=0$ in the S-S model. 
Figure 1.

Links in the Modified Model

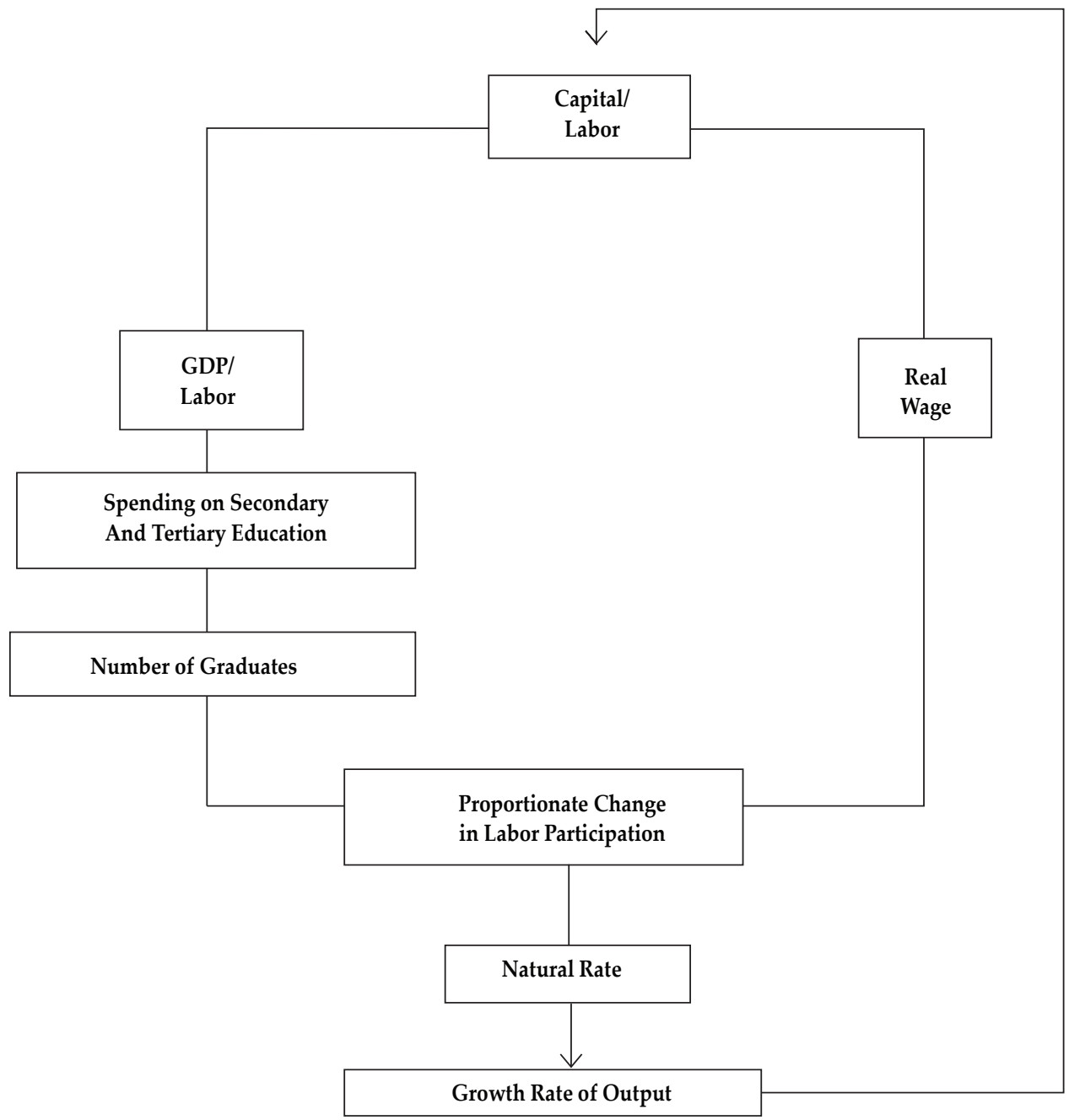

Capital intensity, measured by the capital-labor ratio, has short-run (transitional) and long-run (steady state) effects on output growth through changes in labor participation. The first channel works through an expansion in aggregate income per man-hour resulting from a higher capital-labor ratio, with consequent higher spending on secondary and tertiary education that produces higher number of graduates who enter the labor force. The second channel works through movements in real wage that enter labor supply decisions. A higher capital-labor ratio raises labor's marginal product and hence the real wage, inducing increased labor supply and output growth. The model is closed loop. There is feedback effect of output growth on the capital-labor ratio. Changes in the capital-labor ratio are triggered by discrepancies in the warranted and natural rates, whose weighted average determines the instantaneous output growth rate. 
The structural model is as follows:

$$
\begin{array}{ll}
Y=K^{\alpha} L^{(1-\alpha)} & \text { Aggregate Production Function } \\
\dot{K}=s Y-\delta K & \text { Growth in Capital Stock } \\
\mathrm{L}=\mathrm{APN} & \text { Labor (Efficiency Units } \left.{ }^{9}\right) \\
\dot{N} / N=n & \text { Population Growth } \\
\frac{\dot{A}}{A}=\lambda & \text { Productivity/Technical Change } \\
\frac{\dot{P}}{P}=\beta+\rho\left(\frac{Y}{L}\right)+\omega R W & \text { Change in Labor Participation } \\
\mathrm{RW}=\frac{\partial Y}{\partial L} & \text { Profit Maximization } \\
k=K / L & \text { Capital Intensity }
\end{array}
$$

$Y=$ output (GDP); $K=$ capital stock; $L=$ effective labor (man-hours), $A=$ technology-productivity multiplier; $P=$ labor participation rate (fraction); $N=$ population; $R W=$ real wage; $k=$ capital-labor ratio; $t=$ time (suppressed); $\alpha, s, \delta, \lambda$, $n, \beta, \rho$, and $\omega=$ fixed parameters, with $\rho, \omega>0$. A dot over a variable denotes time derivative, i.e., $\dot{A}=d A / d t$.

\section{A. Discussion}

Equation (8) is the aggregate production function, identical to Equation (1). Using capital and labor, aggregate output is produced according to the Cobb-Douglas function satisfying the Inada (1963) conditions. ${ }^{9}$ Equation (9), which is identical to Equation (2), states that the increment in the capital stock equals gross domestic saving less capital depreciation.

Equation (10) defines effective labor as the product of a technology/ productivity multiplier, $A$, labor participation $P$, and population $N .{ }^{10}$ Equation (11) is the conventional assumption that population grows exogenously at rate $n$. Equation (12) states that technical change grows at a constant rate $\lambda$. Solow (1987) refers to an increase in $\lambda$ as an upward shift in the production function, i.e., more output is produced with the same amounts of capital and labor.

Reflecting the empirical findings of Grigoli et al. (2018) and CBO (2018), Equation (13) postulates that the proportionate change in labor participation, $P$, consists of exogenous component $\beta$ and endogenous components $\rho\left(\frac{Y}{L}\right)$ and $\omega R W$. The exogenous term $\beta$ includes aging and retirements, changes in labor market

\footnotetext{
9 With reference to any production function $F(K, L)=L f(k)$, where $K$ is capital, $L$ is labor, and $k$ is the ratio of $K$ to $L$, these conditions can be summarized as follows: $\lim \partial F / \partial K=\infty$ as $K \rightarrow 0$; $\lim \partial F / \partial K=0$ as $K \rightarrow \infty ; f(0) \geq 0 ; f^{\prime}(k)>0$, and $f^{\prime \prime}(k)<0$ for all $k>0$.

${ }^{10}$ Its time derivative is given by Equation (3).
} 
policies and institutions, e.g., tax-benefits (tax credits and unemployment benefits), and a host of non-economic variables identified in the aforementioned empirical studies. The endogenous terms are: (1) the portion of aggregate income per man-hour $\left(\frac{Y}{L}\right)$ spent on secondary and tertiary education and its effect on the number of graduates, and the latter's effect on the labor participation rate, ${ }^{11}$ and (2) the real wage $R W$ that, under profit maximization, is equal to labor's marginal product $\frac{\partial Y}{\partial L}=(1-\alpha) k^{\alpha}$ as specified in Equation (14), where $k$ is capital intensity, defined as the ratio of $K$ to $L$ in Equation (15). An increase in the real wage is expected to raise the rate of labor participation $(\omega>0)$.

\section{B. Reduced Model}

Dividing Equations (8) and (9) by $K$ and using Equation (15) yield,

$$
\frac{\dot{K}}{K}=s k^{(\alpha-1)}-\delta
$$

Time differentiating Equation (10) and substituting Equations (11)-(15) into the result yield,

$$
\frac{\dot{L}}{L}=[\rho+\omega(1-\alpha)] k^{\alpha}+\lambda+n+\beta
$$

Time differentiating Equation (15) and substituting equations (16) and (17) into the result yield the rate of change of capital intensity,

$$
\frac{\dot{\mathrm{k}}}{\mathrm{k}}=\mathrm{sk}^{(\alpha-1)}-[\rho+\omega(1-\alpha)] \mathrm{k}^{\alpha}-(\lambda+\mathrm{n}+\beta+\delta) .
$$

Time differentiating Equation (8) and substituting Equations (16) and (17) into the result yield the growth rate of output at any moment of time,

$$
\frac{\dot{Y}}{Y}=\mathrm{g}=\alpha s k^{(\alpha-1)}+(1-\alpha)[\rho+\omega(1-\alpha)] k^{\alpha}+(1-\alpha)(\lambda+n+\beta)-\alpha \delta .
$$

The reduced models in $\frac{\dot{k}}{k}, \frac{\dot{K}}{K}$, and $\frac{\dot{L}}{L}$ in the S-S (denoted by s) and modified (denoted by $m$ ) models are shown in Figure 2. The upper part shows the proportionate rate of change in the capital-labor ratio, $k$, and the lower part shows the growth rate of output, Y. Given the Inada (1963) conditions, the $\frac{\dot{k}}{k}$ line in either model is downward-sloping and intersects the $k$-axis at some finite, positive $k$,

\footnotetext{
${ }^{11}$ The coefficient $\rho>0$ is a composite parameter reflecting the fraction of aggregate income spent on secondary and tertiary education and its effect on the number of graduates, and the latter's effect on labor participation.
} 
such as $k_{s}^{*}$ or $k_{m}^{*}$. In either model, for $k<k^{*}, \frac{\dot{k}}{k}>0$, and $k$ increases until it reaches $k^{*}$ at which it becomes constant. For $k>k^{*}, \frac{\dot{k}}{k}<0$, and $k$ decreases until it goes back to $k^{*}$ at which it becomes constant. As capital intensity changes, diminishing marginal and average productivity of capital and positive dependence of labor participation on capital intensity provide the economic rationale behind the proportionate changes in capital intensity and in the warranted and natural rates. Specifically, with reference to the lower part of Figure 2, the downwardsloping warranted rate line in either model owes to diminishing marginal and average capital productivities as $K / L$ increases. The horizontal natural rate line in the S-S model reflects the full exogeneity of technical change. The upwardsloping natural rate line in the modified model reflects the positive dependence of labor participation on $K / L$, i.e., as $K / L$ rises, higher aggregate income per manhour translates into higher spending on secondary and tertiary education, higher number of graduates, and increased labor participation. Additionally, as K/L rises, labor's marginal product goes up and, hence, the real wage increases, encouraging higher labor participation.

Figure 2.

Modified (m) and Solow-Swan (s) Models

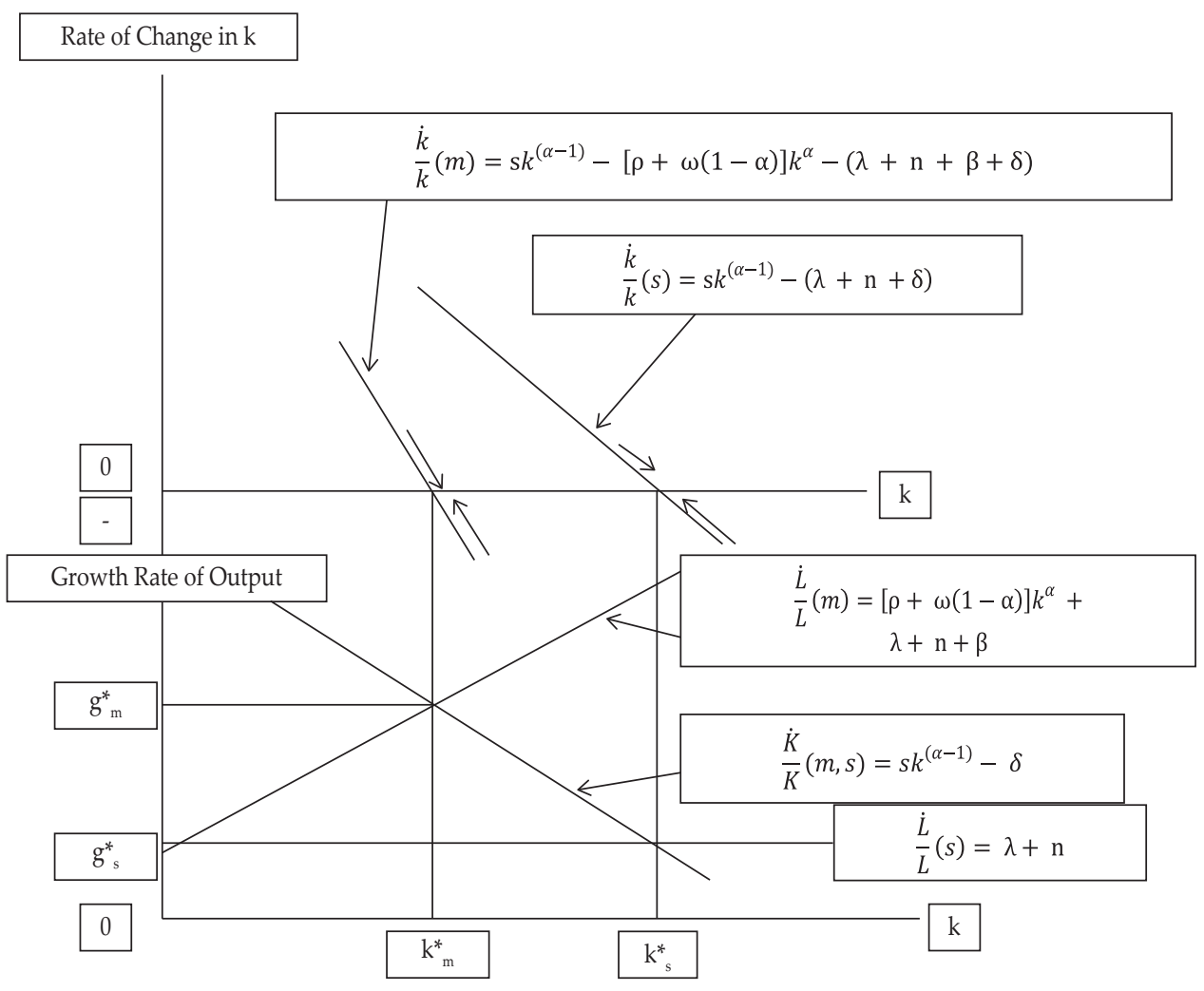


Notice that the $\frac{\dot{k}}{k}(m)$ line is drawn steeper than the $\frac{\dot{k}}{k}(s)$ because of the negative term representing labor participation in the $\frac{k}{k}(m)$ line. The lower panel of Figure 2 shows the equilibrium capital intensity, $k^{*}$, and equilibrium output growth, $g^{*}$, in either model $-k_{s}^{*}$ and $g_{s}^{*}$ and $k_{m}^{*}$ and $g_{m^{*}}$, respectively, in the S-S model and in the modified model. ${ }^{12}$ The equilibrium capital-labor ratio is lesser in the modified model. The intuitive reason is that effective labor in the modified model is larger because of a variable labor participation rate (as opposed to a constant rate in the S-S model). The equilibrium output growth is larger in the modified model because its natural rate is greater for a similar reason. Finally, if labor participation rate is a constant number, such that $\frac{\dot{P}}{P}=0(\beta=\rho=\omega=0)$, then $\frac{\dot{k}}{k}=s k^{(\alpha-1)}-(\lambda+n+\delta)$ and $\frac{\dot{L}}{L}=\lambda+n$, and the modified model collapses into the S-S model.

\section{COMPARATIVE DYNAMICS}

Table 1 shows the steady-state effects of changes in the modified model's parameters on the equilibrium capital intensity and the equilibrium growth rate of per capita output. A higher saving rate and a higher income share going to capital have positive effects on equilibrium capital intensity. Higher values for labor participation, population growth, technical change and physical capital depreciation impact negatively on equilibrium capital intensity.

Table 1.

Sensitivity of $k^{*}$ and $g^{*}-n$ to Parameter Changes

This table reports the sensitivity of $k^{*}=$ equilibrium capital-labor ratio and of $g^{*}-n=$ equilibrium growth rate of per capita GDP to parameter changes to all-else-equal increase in $s=$ saving rate, $\rho=$ response coefficient of labor participation to aggregate spending on secondary and tertiary education, on-the-job training, and skills upgrade, $\omega=$ response coefficient of labor participation to the real wage, $n=$ exogenous population growth, $\lambda=$ exogenous rate of labor-augmenting technical change, $\beta=$ exogenous rate of labor participation, $\delta=$ rate of depreciation of capital, and $\alpha=$ capital share of income.

\begin{tabular}{lllllllll}
\hline Description & $s$ & $\rho$ & $\omega$ & $n$ & $\lambda$ & $\beta$ & $\delta$ & $\alpha$ \\
\hline Change in $k^{*}$ & + & - & - & - & - & - & - & + \\
Change in $g^{*}-n$ & + & + & + & - & + & + & - & - \\
\hline
\end{tabular}

Higher values for the saving rate, labor participation and technical change have positive effects on equilibrium per capita output growth. Rapid population growth, higher capital income share, and an increase in capital depreciation lower equilibrium per capita output growth. ${ }^{13}$

\footnotetext{
12 See Equations (16) and (17).

${ }_{13}$ The $\frac{\dot{k}}{k}(m)=0$ [Equation (18)] is the steady-state condition with an implicit solution for $k^{*}$. The reader can easily check the signs of Table 1 by implicit differentiation of $k^{*}$ in the equation $\frac{\dot{k}}{k}(m)=0$ with respect to the parameters. Substituting such changes in $k^{*}$ into the partial derivatives of $\frac{K}{K} *(m)$ and $\frac{\dot{L}}{L} *$ (m) [Equations (16) and (17), evaluated at $k^{*}$ ] with respect to the parameters determines the signs of the partial derivatives of $g^{*}-n$ with respect to the parameters shown in Table 1.
} 
In the long-run, on the balanced growth path, a (constant) equilibrium capital/ labor ratio $k^{*}=(K / L)^{*}$ means that the warranted and natural rates are equal to each other, and by the constant returns assumption, to the growth rate of output as well:

$$
\frac{\dot{K}}{K} *=\frac{\dot{L}}{L} *=\frac{\dot{Y}}{Y} *=\mathrm{g}^{*}=s k^{*(\alpha-1)}-\delta=[\rho+\omega(1-\alpha)] \mathrm{k}^{* \alpha}+\lambda+\mathrm{n}+\beta .
$$

In the short-run, the output growth rate is a weighted average of the warranted and the natural rates, $\frac{\dot{Y}}{Y}=\alpha \frac{\dot{K}}{K}+(1-\alpha) \frac{\dot{L}}{L}$, derived by time differentiating Equation (8). There is a divergence between the warranted and natural rates in the short-run transition to the next equilibrium. In the S-S model, the natural rate is equal to a constant term: $\frac{\dot{L}}{L}(s)=\lambda+n$; the short-run output growth adjustment falls only on the warranted rate as the capital/labor ratio adjusts to its next equilibrium value. In the modified model, the natural rate adjusts as well to a moving capital/labor ratio, i.e., $\frac{\dot{L}}{L}(m)=[\rho+\omega(1-\alpha)] k^{\alpha}+\lambda+n+\beta$.

\section{A. The Growth Effects of a Higher Saving Rate}

Figure 3 reproduces the lower part of Figure 2, showing the effects of an increased saving rate on equilibrium capital intensity and equilibrium output growth in the S-S and modified models. The starting equilibrium positions are points $B\left(k_{s,}^{*} g_{s}^{*}\right)$ for the S-S model and $A\left(k_{m,}^{*} g_{m}^{*}\right)$ for the modified model. A higher saving rate shifts

Figure 3.

Short-Run and Long-Run Growth Effects of a Higher Saving Rate

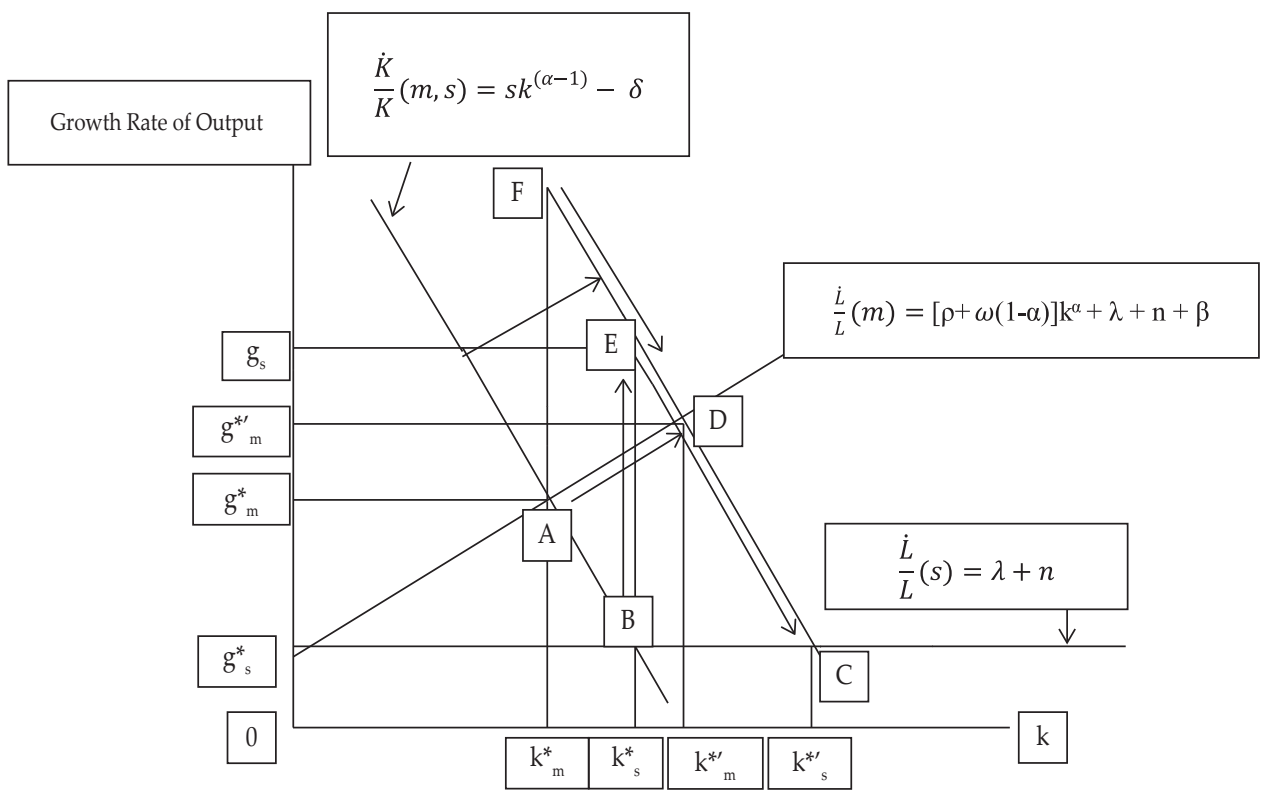


the warranted rate line to the right in either model. The new equilibrium positions are indicated by point $C$ in the S-S model and point $\mathrm{D}$ in the modified model. In both models, the capital/labor ratio goes up, albeit the new ratio remains lower in the modified model than in the S-S model, owing to positive labor participation in the modified model. The key difference is that the new equilibrium output growth increases in the modified model but remains unchanged in the S-S model.

The short-run dynamics of the S-S model is taken up first, followed by that of the modified model. During the steady-state transition between equilibrium points B and C, the S-S output growth rate is momentarily higher than the natural rate $g_{s}^{*}$ at point $E$ because of a higher warranted rate owing to a higher saving rate. ${ }^{14}$ As noted, Figure 3 repeats the lower panel of Figure 2 [see Equations (16) and (17)]. The capital/labor ratio begins to rise from $k^{*}{ }_{s}$ to $k^{* \prime}{ }_{s^{\prime}}$ which slows the warranted rate. Since the natural rate is independent of the capital/labor ratio, only the warranted rate adjusts downward along the segment EC. ${ }^{15}$ Over time, labor becomes a bottleneck, and the output growth rate slows to the constant natural rate $g_{s}^{*}=\lambda+n$ at $\mathrm{C}$. At this point, the capital/labor ratio stops rising and stabilizes at a new and higher level $k^{* \prime}$. Thus, the output growth rate effect of a higher saving rate vanishes in the long-run, and a higher equilibrium capital/labor ratio is the only long-run effect.

In the modified model, following the increase in the saving rate, equilibrium shifts from $A$ to $D\left(k^{* \prime}, g^{* \prime}\right)$. At the starting position $A$, capital grows faster than labor (by the segment $A F$ ), and the capital/labor ratio rises from $k_{m}^{*}$ to $k^{* \prime}{ }_{m}$. The marginal and average products of capital fall, lowering the level of saving per unit of capital, thus slowing the warranted rate downward along the segment FD. On the other hand, the natural rate, instead of remaining constant as in the S-S model, accelerates from $A$ to $D$ along the $\frac{\dot{L}}{L}(m)$ line because of a higher labor participation rate associated with a rising capital/labor ratio. ${ }^{16}$ This process continues until the warranted and natural rates are again equal via a continuous increase in the capital/ labor ratio at the new long-run equilibrium, $D$, at which point the warranted rate would have fallen to the new and higher value of the natural rate, equal to the new and higher equilibrium output growth rate $g^{* \prime}{ }_{m}\left(>g_{m}^{*}\right)$. Thus, unlike in the S-S model, the output growth effect of a higher saving rate does not peter out in the long-run, because of the existence of endogenous labor participation, which makes the natural rate respond positively to an increase in the capital/labor ratio. ${ }^{17}$

\section{B. The Growth Effects of an Increase in Technical Change}

Figure 4 shows the effects of a higher exogenous rate of technical change $\lambda$ on equilibrium capital intensity and equilibrium output growth in the S-S and

\footnotetext{
14 The output growth rate at $E=\alpha g_{s}+(1-\alpha) g_{s}^{*}$.

15 The output growth rate adjustment is traced by the segment BEC in terms of the weighted average of the warranted and natural rates.

16 Through (1) higher $\mathrm{Y} / \mathrm{L}$ and associated higher spending on secondary and tertiary education that increases the size of the educated labor force, and (2) increase in the real wage.

17 The output growth rate adjustment is traced by the weighted average of segments $F D$ and $A D$ as the capital-labor ratio moves from $k_{m}^{*}$ to $k_{m}^{* \prime}$ (weighted by $\alpha$ and 1- $\alpha$, respectively).
} 
modified models. The starting equilibrium positions are points $D\left(k_{s,}^{*} g_{s}^{*}\right)$ for the S-S model and $A\left(k_{m}^{*} g_{m}^{*}\right)$ for the modified model. A higher $\lambda$ shifts the natural rate of the S-S model upward to the $\frac{\dot{L}}{L}(s)=\lambda_{1}+n$ line, a parallel shift from the previous line. The modified model's natural rate shifts upward to the left. The new equilibrium positions are indicated by points $F$ in the S-S model and $C$ in the modified model. In either model, the capital/labor ratio goes down, albeit the new ratio remains lower in the modified model than in the S-S model, owing to positive labor participation in the former. The key difference is that, while the new equilibrium output growth increases to the higher rate of $g_{s}^{* \prime}=\lambda_{1}+n$ in the S-S model, in the modified model the new equilibrium output growth increases to an even higher rate equal to $g_{m}^{* \prime}=g_{s}^{* \prime}+[\rho+\omega(1-\alpha)] k^{* \prime}{ }_{m}^{\alpha}+\beta$.

Figure 4.

\section{Short-Run and Long-Run Growth Effects of an Increase in Technical Change}

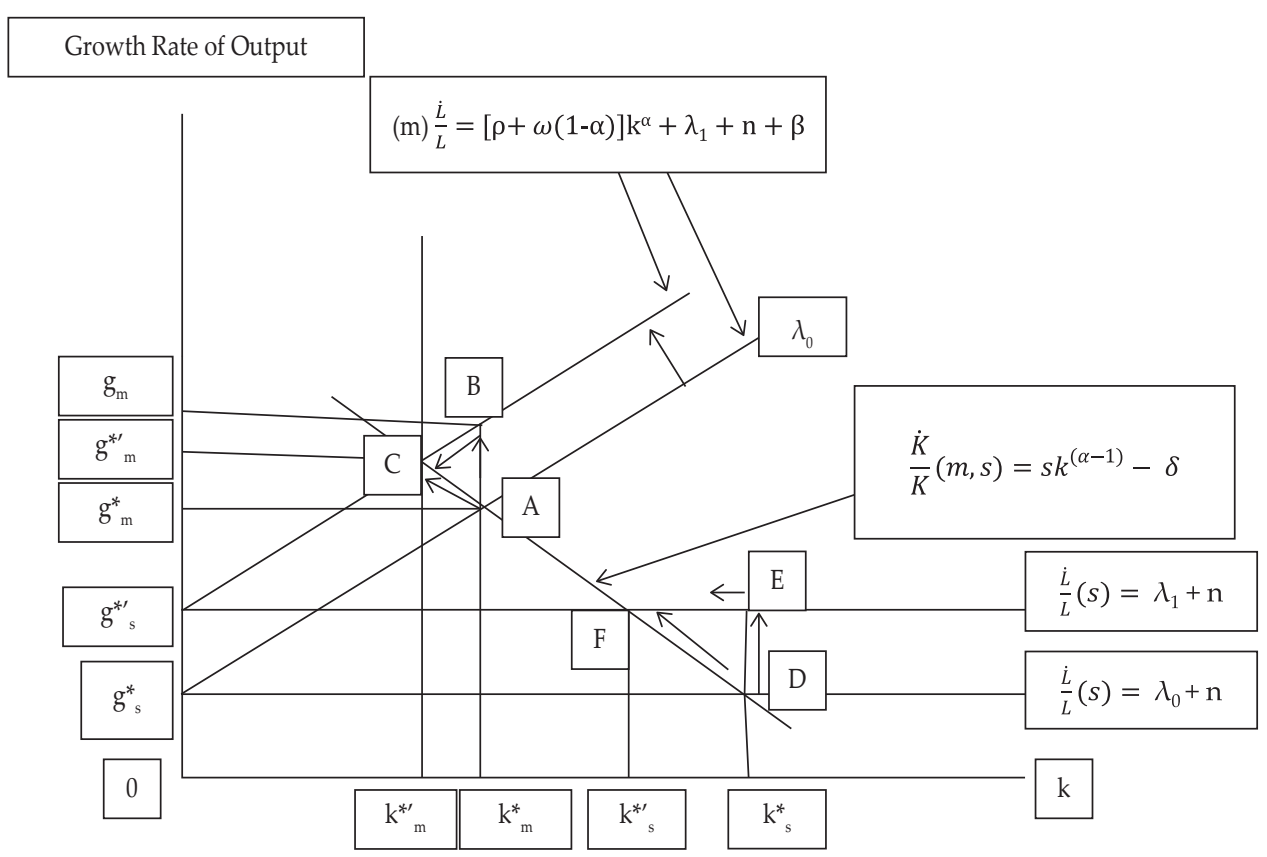

The short-run dynamics of the S-S model is taken up first, followed by that of the modified model. Before the steady-state transition between equilibrium points $D$ and $F$ begins, the natural rate jumps to $\lambda_{1}+n=g^{* \prime}{ }_{s}$ (higher than the warranted rate by the segment $D E$ ), after which the capital/labor ratio begins to fall, raising the warranted rate. Since the natural rate is independent of the capital/labor ratio, the natural rate slides horizontally along the segment $E F$, and only the warranted rate adjusts upward along the segment $D F$ as capital intensity contracts from $k_{s}^{*}$ to $k^{* \prime}$. Over time, as before, labor becomes a bottleneck, and the output growth rate slows to the constant natural rate $g_{s}^{* \prime}=\lambda_{1}+n$ at $F$. At this point, the capital/labor ratio stops falling and stabilizes at a new and lower level $k^{* \prime}$. Thus, the output 
growth rate effect of a higher technical change $\lambda_{1}$ vanishes in the long run, and a lower equilibrium capital/labor ratio is the only long-run effect. ${ }^{18}$

In the modified model, following the increase in technical change, equilibrium shifts from $A$ to $C\left(k^{* \prime}, g^{* \prime}\right)$. At the starting position, $A$, labor grows faster than capital (by the segment $A B$ ), and the capital/labor ratio declines from $k_{m}^{*}$ toward $k^{* \prime}{ }_{m}{ }^{19}$ The marginal and average products of capital rise, raising the level of saving per unit of capital, accelerating the warranted rate upward along the segment $A C$. On the other hand, the natural rate, instead of remaining constant at $\lambda_{1}+n$ as in the S-S model, slows from $B$ to $C$ along the $\frac{\dot{L}}{L}(m)$ line because of a lower labor participation rate associated with a declining capital/labor ratio. ${ }^{20}$ This process continues until the warranted and natural rates are again equal via a continuous fall in the capital/labor ratio at the new long-run equilibrium, $C$, at which point the warranted rate would have risen to the new value of the natural rate, equal to the new and higher equilibrium output growth rate $g^{* \prime}{ }_{m}\left(>g_{m}^{*}\right)$ owing to a higher rate of technical change. Thus, unlike in the S-S model, the output growth effect of a higher rate of technical change does not peter out in the long-run, because of the existence of endogenous labor participation. ${ }^{21}$

\section{The Growth Effects of a Decline in Labor Participation}

Figure 5.

Short-Run and Long-Run Growth Effects of a Decline in Labor Participation (Lower $\rho, \omega$, or $\beta$ )

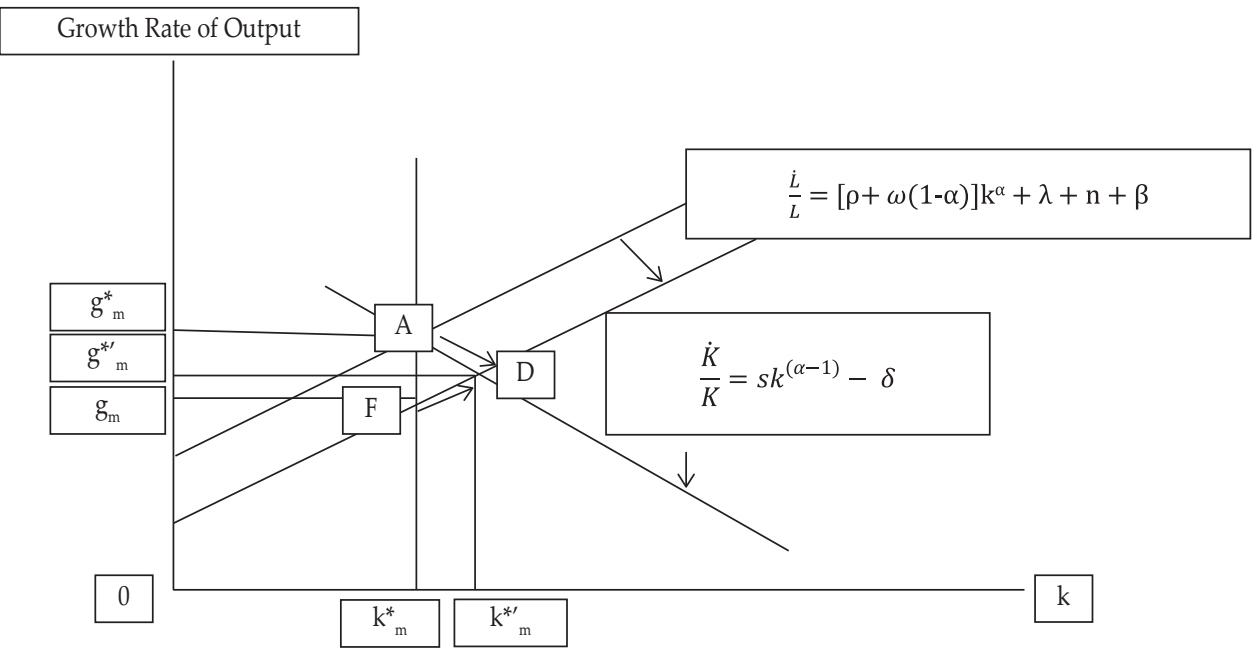

${ }_{18}$ However, see Section V, paragraph 1.

19 The modified model's output growth rate adjustment is traced by the weighted average of segments $B C$ and $A C$, as capital intensity falls from $k_{m}^{*}$ to $k_{m}^{* \prime}$.

20 Through the two channels noted in footnote 17 , but in opposite directions.

${ }^{21}$ In Figure 4, before $\mathrm{k}$ has time to adjust, the output growth rate jumps to $g_{m}=\alpha\left[s k_{m}^{*}{ }_{m}^{(\alpha-1)}-\delta\right]+(1-\alpha)$ $\left\{[\rho+(1-\alpha)] k_{m}^{*}{ }_{m}+\lambda_{1}+n+\beta\right\}$. Thus, an exogenous increase in technical change results in a short-term expansionary overshooting (a burst of short-run output growth, temporarily higher than the next steady state output growth at $g^{* \prime}$ ). 
Figure 5 illustrates the effects of a decline in labor participation as predicted by the $\mathrm{CBO}$ (2018) - a lower $\rho, \omega$, or $\beta$. The initial equilibrium is at point $A$, with capital/ labor ratio $k_{m}^{*}$ and output growth $g_{m}^{*}$. Following the fall in labor participation, the natural rate line shifts downward to the right. Equilibrium shifts from $A$ to $D$. The capital/labor ratio goes up from $k_{m}^{*}$ to ${k^{* \prime}}_{m^{\prime}}$ and the equilibrium output growth goes down from $g^{*}{ }_{m}$ to $g^{*}{ }_{m}$. The increase in the equilibrium capital/labor ratio owes to lower effective labor induced by a lower rate of labor participation. The fall in equilibrium output growth is the result of a lower natural rate line in the face of an unchanged warranted rate line.

Notice that there is an overshooting of the lower output growth rate at $F$ in the short run (in relation to the new long-run growth rate at $D$ ). At the starting capital intensity $k_{m}^{*}$ the natural rate has a precipitous drop to $g_{m}\left(<g^{*}{ }_{m}\right)$ at $F$, following the decline in labor participation. ${ }^{22}$ As the capital-labor ratio begins to rise from $k_{m}^{*}$ to $k^{* \prime}{ }_{m^{\prime}}$ the natural rate recovers along the segment $F D$, while the warranted rate falls along the segment $A D$ because of diminishing marginal and average products of capital. This process continues until the warranted and natural rates are again equal via a continuous increase in the capital/labor ratio at the new long-run equilibrium $D$, where the equilibrium output growth $g^{* \prime}{ }_{m}$ is lower than the initial equilibrium rate $g_{m}^{*}$. One way to restore or even to improve macroeconomic performance is to prevent the decline in, and to encourage higher, labor participation through vigorous implementation of public policies on education, on-the-job training, upgrading skills for a digital economy, real wage increases in line with labor productivity, and other labor market participation initiatives identified by Grigoli et al. (2018) and CBO (2018)..$^{23}$

\section{RELATED ISSUES}

Econometric evidence pointing to positive growth effects of the saving rate may be consistent with the transitional dynamics of the Solow-Swan model, in view of the absence of substantially long-run data on a large sample of countries. Thus, even on empirical grounds, the issue is far from settled. On the S-S transitional growth dynamics, Solow (1991, p. 4) remarks: "Imagine an economy that has a constant, unchanging level of productivity. Then something happens - the invention of a computer, for instance-and productivity begins to rise. We know it will reach a new plateau and level off there. Then it will become constant again, higher than it was before but no longer changing. Such a process might take thirty years or even longer for a major invention. If you look at the annual growth rate, it will start at zero, build up to a positive value, perhaps quite suddenly, then start to fall back and reach zero again after thirty years have passed. Should we classify it as an episode of temporary growth or as something else? It is not surely a steady state. Such one-time gains in productivity are very valuable achievements." Solow (1991), in describing the "new growth" theory (Romer, 1986, 1990, Lucas ,1988,

${ }^{22}$ In Figure 5, before $k$ has time to adjust, the output growth rate falls to $g_{m}=\alpha\left[s k_{m}^{*(\alpha-1)}-\delta\right]+(1-\alpha)$ $\left\{[\rho+(1-\alpha)] k_{m}^{*}{ }_{m}+\lambda+n+\beta\right\}$. Thus, a decline in labor participation results in a short-term contractionary overshooting (lower short-run output growth, temporarily less than the next steady state output growth at $\left.g_{m}^{* \prime}\right)$.

${ }^{23}$ Working through calibrated changes in the parameters $\rho, \omega$, and $\beta$. 
among others), vs. the "older growth" theory (Solow 1956, Swan 1956), observes, "The theory differentiated sharply between policies that could lift the potential trend curve from those that could tilt the curve, i.e., change the rate of growth." (italics in the original, pp. 8-9). The modified Solow-Swan model of the current paper not only lifts the potential (natural rate) curve but also tilts the curve in Figure 3 because of endogenous labor participation.

Another issue relates to the empirical validation of the modified model. Table 1 and Figures 3 and 5 show the dynamics of the growth effects of the saving rate and labor participation rate. The signs and magnitudes of such predictions can be empirically tested. All explanatory variables are observables, except for the technical change parameter $\lambda$, which can be impounded in the constant term of the growth regressions. This is a subject for future research. ${ }^{24}$

\section{CONCLUSION}

The paper's main conclusion is that endogenous labor participation ensures a fully adjusting natural rate together with a fully adjusting warranted rate of the S-S model. Thus, the steady-state growth rate of output and the steady-state level of the capital-labor ratio are functions of all the structural parameters, including the saving rate. The growth effects of an increased saving rate do not disappear in the long run, even when technical change and population growth are fully exogenous. One by-product is a new result: The CBO (2018) projected decline in labor participation over the next decade will result in a lower long-run per capita output growth path, with short-run recessionary overshooting.

The paper also derives the simple analytics of the short-run and long-run output growth effects of a decline in labor participation, as projected by the CBO (2018). In the short-run, there is an overshooting of recessionary growth. In the long-run, there is an eventual return to a permanently lower growth path. ${ }^{25}$ Policies to restore the previous growth path or to achieve a higher growth path involve avoiding the projected fall in labor participation by aggressive and calibrated spending on secondary and tertiary education, on-the-job training, and skills upgrade to a fullfledged digital economy (a higher $\rho$ ), steady increases in real wages in line with labor productivity (a higher $\omega$ ), vigorous labor market participation activities and more generous tax-benefits (higher $\beta$ ), in order to offset the negative effects of aging and retirements (lower $\beta$ ).

${ }^{24}$ Panel data regressions (temporal and cross-country) would be appropriate to use in order to draw out the short-run and long-run growth effects of the independent variables.

${ }^{25}$ Section IV.B discusses the opposite scenario showing the growth effects of an increase in exogenous technical change. In the short run, there is an expansionary output growth overshooting, followed by a permanently higher output growth path in the long run (in relation to the initial growth equilibrium). 


\section{ACKNOWLEDGMENT}

I am indebted to Diwa Guinigundo, Thorvaldur Gylfason, Lee Endress, Joshua Greene and two anonymous referees for valuable comments.

\section{REFERENCES}

Agenor, P. (2004). The Economics of Adjustment and Growth. Harvard University Press, Cambridge, MA.

Aghion, P., and Howitt, P. (1998). Endogenous Growth Theory. MIT Press, Cambridge, MA.

Arrow, K. (1962). The Economic Implications of Learning by Doing. Review of Economic Studies, 29, 155-173.

Congressional Budget Office. (2018). CBO's Projection of Labor Force Participation Rates. Working Paper No. 2018-04, March 16.

Conlisk, J. (1967). A Modified Neoclassical Growth Model with Endogenous Technical Change. Southern Economic Journal, 34, 199-208.

Domar, E. (1946). Capital Expansion, Rate of Growth, and Employment. Econometrica, 14, 137-147.

Grigoli, F., Koczan, Z. and Tapalova, P. (2018). Drivers of Labor Participation: Macro and Micro Evidence. International Monetary Fund Working Paper. WP/18/150. Washington, D.C.

Grossman, G., and Helpman, E. (1991). Innovation and Growth in the Global Economy. MIT Press, Cambridge, MA.

Harrod, R. (1939). An Essay in Dynamic Theory. The Economic Journal, 49, 14-33.

Inada, K-I. (1963). On a Two-Sector Model of Economic Growth: Comments and Generalization. Review of Economic Studies, 30, 119-127.

Lucas, R. (1988). On The Mechanics of Economic Development. Journal of Monetary Economics, 22, 3-42.

Nelson, R., and Phelps, E. (1966). Investment in Humans, Technological Diffusion, and Economic Growth. American Economic Review, 56, 69-75.

Rebelo, S. (1991). Long-Run Policy Analysis and Long-Run Growth. Journal of Political Economy, 99, 500-21.

Romer, P. (1986). Increasing Returns and Long-Run Growth. Journal of Political Economy, 94, 1002-37.

Romer, P. (1990). Endogenous Technical Change. Journal of Political Economy, 98, s71-s102.

Solow, R. (1956). A Contribution to the Theory of Economic Growth. Quarterly Journal of Economics, 70, 65-94.

Solow, R. (1987). Growth Theory and After. Nobel Prize Lecture, December 8.

Solow, R. (1991). Policies for Economic Growth. Ernest Sturc Memorial Lecture. SAIS, Johns Hopkins University. November 12.

Swan, T. (1956). Economic Growth and Capital Accumulation. Economic Record, 32, 334-362.

Villanueva, D. (1994). Openness, Human Development and Fiscal Policies. IMF Staff Papers, 41, 1-29.

Warsh, D. (2007). Knowledge and the Wealth of Nations: A Story of Economic Discovery. 
W.W. Norton and Company, New York. 